\title{
A Conversation with Daniela Schiller
}

\author{
INTERVIEWER: JAN WITKOWSKI \\ Cold Spring Harbor Laboratory
}

\begin{abstract}
Daniela Schiller is an Associate Professor in the Departments of Neuroscience and Psychiatry at the Icahn School of Medicine at Mount Sinai.
\end{abstract}

\begin{abstract}
Jan Witkowski: You work a little bit outside the sort of normal hardcore molecular neuroscience that we usually hear about.
\end{abstract}

Dr. Schiller: My research is on navigating "social space" and our "model system" is the human brain. Our behavioral protocols are probably more naturalistic and complex, but they are tightly linked to knowledge gained from basic neuroscience, in particular, regarding the spatial navigation system. We examine the hippocampus and related areas that are dedicated to navigating physical space. Similar areas are also implicated in episodic memory, and it is unclear how the two functions are related or why they are subserved by similar brain regions. One idea is that these systems perform a relational computation: They track statistical regularities and relationships between continuous dimensions. We took this idea into the domain of social relationships because social interactions could be framed as trajectories evolving in a two-dimensional social space framed by power and affiliation.

Jan Witkowski: What exactly do you mean by social space?

Dr. Schiller: If we want to describe a social space we should first define the dimensions of social space: We know from social psychology theory and ethology studies across species that the main factors that drive social relationships are "power" and "affiliation."

Jan Witkowski: Your focus is on social relationships between people.

Dr. Schiller: Yes, for example, we could ask ourselves why are we meeting here in this conference? Why don't we just sit at home and listen to audio-recorded lectures or read each other's papers? Probably because we wish to interact. Interactions drive and shape our social environment, which would otherwise remain static. We can therefore view the people we interact with as "locations" in this abstract social space; when we interact with them, they move about, and we need to track that movement. We have to keep note of the changes in relative power and affiliation people have in relation to us. Without tracking these social trajectories and how our relationships evolve over time along these dimensions, we might develop problems with social behaviors, as we see in many psychiatric disorders.

Jan Witkowski: You're treating this social space in a real physical way, not as an abstract thing? I can think about spatial relations to buildings and things, the physical objects the brain relates. You're applying that sort of analysis to the social space of human interactions?

Dr. Schiller: Exactly, we believe that the same neural computation applies to physical space and beyond. Physical space could be regarded as one case of relational computation, but this could apply to other manner of spaces, including the social. For example, there is evidence for spatial-like computations in olfactory space, auditory space, and even just arbitrary space, as long as relationships between continuous dimensions are needed to be tracked and navigated through.

Jan Witkowski: You're using human subjects. What sort of experiments or observations do you do to explore this field?

Dr. Schiller: We try to do something rather naturalistic. If you are a participant, you would come to our lab, slide into the fMRI [functional magnetic resonance imaging] scanner, and play a social interaction game. The storyline is constructed like one of those "choose your own adventure" games we used to play as kids: People get the same narrative, but they make choices on how to interact with the characters, and therefore each participant will experience the narrative differently. For example, in one such situation, one of our characters approaches you, reminds you that you were friends a long time ago, and goes for a hug. Then you need to decide if you hug her for a long moment or just give her a brief pat on the back. This is an opportunity to shape your social space. In this "affiliation" interaction, if you hug her for a long moment, you got closer. In some of the "power" interactions there's a boss character, a person very powerful in town. That person can give you a job but can also be very dominant. Here again you have a choice-whether to be submissive or not. If you are, then that character moves up

(C) 2018 Schiller. This article is distributed under the terms of the Creative Commons Attribution-NonCommercial License, which permits reuse and redistribution, except for commercial purposes, provided that the original author and source are credited. 
on the "power" axis, changing "location" in your social space.

Then, we take our participants' choices and plot them on that two-dimensional space, which gives us "social coordinates." This allows us to measure the orientation and length of a vector between yourself and the character. We basically translate your social behavior into a geometric structure. You interact with the characters, and we represent your social decisions as "movement" on these two dimensions. Then we can ask, "Are these social-coordinate values being tracked by the brain?" Indeed, we found that the vector angle, which indicates the orientation (or angle) of the vector, was tracked by the hippocampus; and the vector length was tracked by the posterior cingulate cortex.

Jan Witkowski: Coming back to the lady being hugged, the relationship between the hugger and the huggee is part of the narrative, whether they've known each other since school or they've just met at a party. Is that the sort of narrative that you change to look at how the relationship changes depending on that?

Dr. Schiller: Yes, the exact narrative you end up experiencing is determined by your own choices. If you hug her, then the narrative continues with that long hug. Another participant might push her away and then persist in doing so in the following interactions. This is how you would form a certain trajectory with each character. Imagine a "cube" with a "power" dimension, an "affiliation" dimension, and a "time" dimension indicting power and affiliation at each and every interaction throughout the game. You would get a branch-like geometric structure unique to each participant. In addition to examining how the brain is tracking these social trajectories, we might identify geometric parameters in that structure. For example, how narrow or large the space is, whether it has a particular orientation and so forth. These geometric qualities of the space might indicate social skills and social behavior tendencies.

Jan Witkowski: What sort of subjects have you used in these studies?

Dr. Schiller: We have published one study examining the neural tracking of social coordinates in healthy volunteers. We are now moving on to various clinical populations.

Jan Witkowski: In your healthy volunteers, do you deliberately aim for subjects who themselves are different in their nature? I mean, I tend to be a very friendly sort of person. Do you get people who are rather cold or bossy?

Dr. Schiller: The study is open to all types of people. We had some participants, for example, that were very hierarchical in nature. You could see how at the end of the game the characters were neatly sorted along the proper dimen- sion. Some people pushed most characters away and got close to one character in particular. Some had a very narrow space, meaning that they didn't get very far with any character but rather back and forth in power and affiliation. So, in a way, we could see "personalities" in the individual social maps. This is one interesting aspect of the study, possibly allowing us to move toward "precision" research, providing tools for personalized treatment.

Jan Witkowski: You have mentioned working with people with mental disorders; can you tell me more about it?

Dr. Schiller: Yeah, for example, we have started examining patients with disorders of borderline personality, avoidant personality, and schizotypal personality. These are patients that are predominantly characterized by problems in interpersonal relationships. For example, borderline patients often experience very intense and unstable relationships. Other studies are conducted in schizophrenia patients, where social deficits might emerge early on even before people are diagnosed as schizophrenics. Autism is another disorder that includes social impairment, which we're currently looking at using these new social space measures.

It is interesting to note that in many psychiatric disorders, social impairment and hippocampal dysfunction co-occur. Moving forward, we would like to connect the two-hippocampal dysfunction and social dysfunctionand examine whether and how they're linked across psychiatric disorders.

Jan Witkowski: It's essentially like video games, the setup? People, including people with mental disorders, do interact with these characters as though they were real people. They become attached or distant. What I'm getting at is, they don't regard these as a game. They become emotionally immersed in the interactions?

Dr. Schiller: I believe so. This is why we chose to engage the participants with a storyline. Narratives are powerful in drawing you into a story. People have a natural tendency to follow storylines and get emotionally involved with characters in stories.

Jan Witkowski: Do you think this sort of analysis could be used for preclinical diagnosis, that you could detect signs of schizophrenia in somebody before they were showing much in the way of features of the disorder?

Dr. Schiller: This is an interesting possibility. One of our future goals is to examine the social game in a wide variety of people from the general population-hundreds of people from various walks of life - to quantify people's social behavior and the way in which it relates to psychological abnormalities. Delineating the normative social space in the general population and how it relates to psychological traits might give us a tool for preclinical diagnosis. 


\section{$\$_{\text {CSH\& }}^{\infty}$ Cold Spring Harbor Symposia SYMPOSIA}

\section{A Conversation with Daniela Schiller}

Cold Spring Harb Symp Quant Biol 2018 83: 275-276 originally published online February 25, 2019

Access the most recent version at doi:10.1101/sqb.2018.83.037606
Creative This article is distributed under the terms of the
Commons http://creativecommons.org/licenses/by-nc/4.0/, which permits reuse and
License redistribution, except for commercial purposes, provided that the original author and source are credited.

Email Alerting Receive free email alerts when new articles cite this article - sign up in Service the box at the top right corner of the article or click here. 